\section{(6)} OPEN ACCESS

\title{
Pharmacy services at the PyeongChang 2018 Olympic and Paralympic Winter Games
}

\author{
Mark Stuart, ${ }^{1}$ Young In Kwon, ${ }^{2}$ Sandy Jeong Rhie ${ }^{\oplus 3,4,5}$
}

${ }^{1}$ IOC Medical Commission Games Group

${ }^{2}$ Department of Pharmacy, Wonju Severance Christian Hospital, Wonju, Republic of Korea

${ }^{3}$ College of Pharmacy and Division of Life \& Pharmaceutical Sciences Graduate School, Ewha Womans University, Seoul, Republic of Korea

${ }^{4}$ Department of Pharmacy, Ewha Womans University Mokdong Hospital, Seoul, Republic of Korea

${ }^{5}$ Yonsei Institute of Sports Science and Exercise Medicine (YISSEM), Yonsei University, Wonju, Republic of Korea

Correspondence to Professor Sandy Jeong Rhie, College of Pharmacy and Division of Life \& Pharmaceutical Sciences Graduate School, Ewha Womans University, Seoul, Republic of Korea; sandy.rhie@ewha.ac.kr

Accepted 17 February 2019 Published Online First 20 March 2019

\begin{abstract}
Objective Pharmacy services at large multisport events support safe and effective medication use. Our aim is to describe the contribution of pharmacists and to share the pharmacy experiences at the 2018 PyeongChang Olympic and Paralympic Games.

Methods The data collected included the accreditation details of patients and prescribers indicating: sport, country, athlete or non-athlete status, and prescription details including: medication, strength, frequency, length of treatment, for the period of the Olympic Games (1-26 February 2018) and the Paralympic Games (5-20 March 2018). The numbers of prescriptions dispensed were analysed by medication category, sports and country of the patient.
\end{abstract}

Results A total of 5313 medication items were dispensed over the course of the Olympic and Paralympic Games (athletes: 670; non-athletes: 4615; unknown: 28), for a total of 2360 patients. 72 of 82 countries (87.8\%) had fewer than 20 patient visits. The first high peak (Olympic: $5.0 \%$; Paralympic: $7.3 \%$ ) of daily volume of prescriptions were dispensed in the 2 days prior to the Olympic and the 1 day prior to Paralympic opening ceremonies. Therapeutic Use Exemption (TUE) and International Olympic Committee NeedlePolicy were well managed and compliant with the regulations.

Conclusion Pharmacy services at major multisport games include dispensing over 5000 prescriptions, supporting the TUE and IOC Needle Policy processes and providing clinical information to athletes and prescribers on drugs in sports and the World Anti-Doping Agency regulations of drugs prohibited in sport. During the PyeongChang 2018 Olympic and Paralympic Winter Games, pharmacists played a crucial role in delivering safe and effective pharmacy service based on their expert knowledge in antidoping and the clinical use of drugs in sport.

\section{INTRODUCTION}

The PyeongChang 2018 Olympic and Paralympic Winter Games were staged between February and March 2018 in PyeongChang, South Korea. A total of 2914 athletes from 92 countries competed in the Olympic Winter Games, and 569 athletes from 49 countries competed in the Paralympic Winter Games.

The key function of the pharmacy service was to support safe and effective dispensing of medications to athletes and other supporting members of the Olympic and Paralympic Games. ${ }^{12}$ The fundamental principle of protecting the health of the athlete, in accordance with the Olympic/Paralympic Movement Medical Code, respectively, was at the forefront of the pharmacy service mission.

In addition to dispensing medications, the pharmacy service played an active role in ensuring prescription medications and the administration were according to the rules under the World AntiDoping Agency (WADA) Code and List of Prohibited Substances and Methods. ${ }^{4-6}$ In accordance with the International Olympic Committee (IOC) Needle Policy, the administration of any injectable medication to athletes was declared by the team physician during the Olympic Games.

The purchase, safe storage and distribution of medications including controlled medications to the athlete and spectator medical facilities at the competition venues were some of the key tasks performed by the pharmacy services. ${ }^{7}$ This included systems for the storage and issue of controlled medications, according to Korean laws.

The unique role of the pharmacy team contributed to ensuring a safe and healthy environment for the athletes, especially relating to illness prevention interventions and public health, and also including the pharmacological management of infectious illnesses among the athletes in the villages. The aim of this article is to provide organisers of future games with practical insights into the pharmacy operations, and the contribution of pharmacists at large multisport events.

\section{METHODS}

Patient involvement

None.

Anonymised patient medication data were assessed.

Data collection and analysis

Each prescription entry was reviewed and reported prospectively on daily basis from 1 February 2018 to 26 February 2018 for the operational period of the Olympic Games and between 5 March 2018 and 20 March 2018 for the Paralympic Games. At the end of the Games, anonymised data were collected, which included the accreditation numbers of patients and prescribers, prescription date, medication name, strength, frequency, duration of the treatment course, sports participated, whether the patient was an athlete or a non-athlete, and the countries of patients presenting at the pharmacy. An electronic pharmacy dispensing software program, PharmIT3000, donated by the Korea Pharmaceutical Information Center of the Korea Pharmaceutical Association, was used over the course of the Olympic and Paralympic Games. We generated daily reports of the list of medications dispensed and evaluated frequently prescribed medications, and the number of patient visits by country and sports. Medications were classified by therapeutic categories and administration routes. 
Original article

Table 1 Patient encounters and prescriptions dispensed during the Olympic and Paralympic Games

\begin{tabular}{lcc}
\hline & Olympic Games, $\mathbf{n}(\%)$ & Paralympic Games, $\mathbf{n}(\%)$ \\
\hline Prescriptions & 4364 & 949 \\
\hline Athletes & $613(14.0)$ & $57(6.0)$ \\
\hline \multicolumn{1}{c}{ Non-athletes } & $3723(85.3)$ & $892(94.0)$ \\
\hline Unknown & $28(0.6)$ & $0(0.0)$ \\
Visits & 1965 & 395 \\
\hline \multicolumn{1}{c}{ Athletes } & $300(15.3)$ & $33(8.4)$ \\
\hline Non-athletes & $1665(84.7)$ & $362(91.6)$ \\
\hline Unknown & $16(0.8)$ & $0(0.0)$ \\
Countries & 120 & 48 \\
Sports & 19 & 8 \\
\hline
\end{tabular}

Pharmacy vigilance, Therapeutic Use Exemption and Needle Policy

The pharmacy team monitored several designated medications such as oseltamivir, loperamide and sudden increases in the volume of prescriptions, and, if any, we reported signs of illness like diarrhoea or body aches to the public health experts in the polyclinic to aid public health surveillance. The prescription trend was followed daily, and any significant observations were also communicated to the IOC Medical Commission and International Paralympic Committee (IPC) Medical Committee, respectively, for review.
When Therapeutic Use Exemption (TUE) applications were dropped off in the pharmacy, the pharmacist was responsible for locking the form in a secure safe until collected by the TUE committee and providing proof of receipt to the person submitting it. After a TUE was approved by the TUE Committee, the prescriber would write the appropriate prescription and the pharmacy would dispense the prescription in consultation with the prescribing team doctor and athlete.

Team doctors prescribing injectable medications during the Olympic Games were told that they must declare the medication on an IOC Needle Use Declaration Form if they were to be administered outside of the polyclinic, according to the IOC Policy.

Data analysis

Pharmacy data were analysed with MS Excel by prescriptions dispensed according to the medication therapeutic category, country of the patient and the sport if the patient was an athlete. The volume of prescriptions between the Olympic and Paralympic Games was reported in a descriptive statistics.

\section{RESULTS}

\section{Medication use}

A total of 5313 prescription items were dispensed over the course of the Olympic and Paralympic Games (Olympics: 4364; Paralympics: 949) for a total of 2360 patients. The

Table 2 Total prescriptions dispensed in the top five medication categories

\begin{tabular}{|c|c|c|c|}
\hline & $\begin{array}{l}\text { Overall } \\
n=4494 \\
n(\%)\end{array}$ & $\begin{array}{l}\text { Olympic Games } \\
n=3570 \\
n(\%)^{*}\end{array}$ & $\begin{array}{l}\text { Paralympic Games } \\
\mathrm{n}=924 \\
\mathrm{n}(\%) \dagger\end{array}$ \\
\hline Analgesics and anti-inflammatory agents & $1357(30.2)$ & $1102(25.3)$ & $255(26.9)$ \\
\hline NSAIDs & $808(59.5)$ & $680(61.7)$ & $128(50.2)$ \\
\hline Acetaminophen/propacetamol & $455(33.5)$ & $339(30.8)$ & $116(45.5)$ \\
\hline Tramadol & $34(2.5)$ & $28(2.5)$ & $6(2.4)$ \\
\hline Glucocorticoids (oral) & $0(0.0)$ & $0(0.0)$ & $0(0.0)$ \\
\hline Others & $60(4.4)$ & $55(5.0)$ & $5(2.0)$ \\
\hline Respiratory agents & $984(21.9)$ & $791(18.1)$ & $193(20.3)$ \\
\hline Antihistamines & $485(49.3)$ & $388(49.1)$ & $97(50.3)$ \\
\hline Antitussives & $347(35.3)$ & $263(33.2)$ & $84(43.5)$ \\
\hline Common cold & $109(11.1)$ & $97(12.3)$ & $12(6.2)$ \\
\hline Decongestants & $43(4.4)$ & $43(5.4)$ & $0(0.0)$ \\
\hline Gastrointestinal agents & $921(20.5)$ & $711(16.3)$ & $210(22.1)$ \\
\hline Antiulcer & $650(70.6)$ & $515(72.4)$ & $135(64.3)$ \\
\hline Digestive & $164(17.8)$ & $124(17.4)$ & $40(19.0)$ \\
\hline Antidiarrhoeal & $90(9.8)$ & $58(8.2)$ & $32(15.2)$ \\
\hline Constipation & $17(1.8)$ & $14(2.0)$ & $3(1.4)$ \\
\hline Topical/local & $804(17.9)$ & $610(14.0)$ & $194(20.4)$ \\
\hline Glucocorticoids & $236(29.4)$ & $182(29.8)$ & $54(27.8)$ \\
\hline Glucohexidine & $209(26.0)$ & $174(28.5)$ & $35(18.0)$ \\
\hline Carboxymethyl cellulose/hyaluronic acid & $209(26.0)$ & $147(24.1)$ & $62(32.0)$ \\
\hline Antibacterial/viral & $142(17.7)$ & $99(16.2)$ & $43(22.2)$ \\
\hline Antifungal & $8(1.0)$ & $8(1.3)$ & $0(0.0)$ \\
\hline Antimicrobials (systemic) & $428(9.5)$ & $356(8.2)$ & $72(7.6)$ \\
\hline Antibacterials & $331(77.3)$ & $263(73.9)$ & $68(94.4)$ \\
\hline Antivirals & $97(22.7)$ & $93(26.1)$ & $4(5.6)$ \\
\hline Antifungals & $0(0.0)$ & $0(0.0)$ & $0(0.0)$ \\
\hline
\end{tabular}

${ }^{*}$ percentage in Olympic $=\frac{\text { Number of prescription dispensed in the category during Olympic }}{\text { Total number of prescriptions during Olympic }}$

†percentage in Paralympic $=\frac{\text { Number of prescription dispensed in the category during Paralympic }}{\text { Total number of prescriptions during Paralympic }}$

NSAIDS, non-steroidal anti-inflammatory drugs. 
Table 3 Prescriptions dispensed to athletes

\begin{tabular}{|c|c|c|c|}
\hline & $\begin{array}{l}\text { Overall } \\
n=670 \\
n(\%)^{*}\end{array}$ & $\begin{array}{l}\text { Olympic Games } \\
n=613 \\
n(\%)^{*}\end{array}$ & $\begin{array}{l}\text { Paralympic Games } \\
n=57 \\
n(\%) \dagger\end{array}$ \\
\hline Analgesics and anti-inflammatory agents & $214(31.9)$ & $198(32.3)$ & $16(28.1)$ \\
\hline NSAIDs & $148(69.2)$ & $138(69.7)$ & $10(62.5)$ \\
\hline Acetaminophen/propacetamol & $43(20.1)$ & $39(19.7)$ & $4(25.0)$ \\
\hline Tramadol & $15(7.0)$ & $13(6.6)$ & $2(12.5)$ \\
\hline Glucocorticoids (oral) & $6(2.8)$ & $6(3.0)$ & $0(0.0)$ \\
\hline Others & $2(0.9)$ & $2(1.0) \ddagger$ & $0(0.0)$ \\
\hline Respiratory agents & $136(20.3)$ & $128(20.9)$ & $8(14.0)$ \\
\hline Antihistamines & $62(45.6)$ & $58(45.3)$ & $4(50.0)$ \\
\hline Antitussives & $35(25.7)$ & $32(25.0)$ & $3(40.0)$ \\
\hline Common cold & $14(10.3)$ & $13(10.2)$ & $1(10.0)$ \\
\hline Decongestants & $25(18.4)$ & $25(19.5)$ & $0(0.0)$ \\
\hline Topical/local & $112(16.7)$ & $98(16.0)$ & $14(24.6)$ \\
\hline Glucocorticoids & $14(12.5)$ & $12(12.2)$ & $2(14.3)$ \\
\hline Glucohexidine & $45(40.2)$ & $43(43.9)$ & $2(14.3)$ \\
\hline Carboxymethyl cellulose/hyaluronic acid & $34(30.4)$ & $24(24.5)$ & $10(71.4)$ \\
\hline Antibacterial/viral & $19(17.0)$ & $19(19.4)$ & $0(0.0)$ \\
\hline Gastrointestinal agents & $103(15.4)$ & $96(15.7)$ & $7(12.3)$ \\
\hline Antiulcer & $84(81.6)$ & $78(81.3)$ & $6(85.7)$ \\
\hline Digestive & $9(8.7)$ & $9(9.4)$ & $0(0.0)$ \\
\hline Antidiarrhoeal & $10(9.7)$ & $9(9.4)$ & $1(14.3)$ \\
\hline Antimicrobials (systemic) & 85 (12.7) & $74(12.1)$ & $11(19.3)$ \\
\hline Antibacterials & $62(72.9)$ & $51(68.9)$ & $11(100)$ \\
\hline Antivirals & $23(27.1)$ & $23(31.1)$ & $0(0.0)$ \\
\hline Others & $20(3.0)$ & $19(3.10) \S$ & $1(1.75) \emptyset$ \\
\hline
\end{tabular}

* percentage in Olympic $=\frac{\text { Number of prescription dispensed in the category during Olympic }}{\text { Total number of prescriptions during Olympic }}$

†percentage in Paralympic $=\frac{\text { Number of prescription dispensed in the category during Paralympic }}{\text { Total number of prescriptions during Paralympic }}$

$\ddagger$ Gabapentin.

§Amlodipine, ferrous sulfate, levonorgestrel, metformin, reconstitution fluids, salbutamol, vaccines and warfarin.

ITopical antianginal.

NSAIDS, non-steroidal anti-inflammatory drugs.

vast majority of prescriptions were written by the polyclinic medical staff (table 1 ).

The most frequently dispensed therapeutic medications are listed in table 2. These were analgesics and anti-inflammatories, which were prescribed at a similar rate between the Olympic and Paralympic Games (Olympics n=1102 [25.3\%]; Paralympics: $n=255[26.9 \%])$. It was followed by symptomatic treatment for respiratory agents such as antihistamines, combination formulation for common cold and antitussives (Olympics $n=791$ [18.1\%]; Paralympics $n=193$ [20.3\%]) and antivirals (Olympics $\mathrm{n}=93$ [26.1\%]; Paralympics n=4 [5.6\%]) were more prescribed during the Olympics. The higher numbers of this class of medications during the Olympics could be attributed to the severely cold temperature (around $-20^{\circ} \mathrm{C}$ ) and the reports of influenza and norovirus infection outbreaks in a local area during the Olympic Games. Higher use of chlorohexidine gargle for throat symptoms may be attributed to the same reason (Olympics $\mathrm{n}=174$ [28.5\%]; Paralympics n=35 [18.0\%]) (table 2).

Medications dispensed to athletes were checked for their prohibited or permitted status in sports, and the athlete was advised if TUE was required for the medication. The website www.globaldro.com was used as a primary reference to support the pharmacy team to check the WADA status of the medications dispensed. The prescriptions dispensed to athletes are summarised in table 3.

Mouth gargles and eye drops for dry eyes were frequently prescribed, possibly due to dry winter weather and heating (tables 2 and 3). The number of oseltamivir prescriptions dispensed was tracked closely in order to detect any indications of a potential outbreak of influenza among the residents of the athlete villages. We found that a total of 97 oseltamivir prescriptions were issued and only 2 cases were indicated for treatment, while the remaining were intended as a prophylactic measure for influenza viral infection. Antidiarrhoeal medications were also monitored due to the concerns of norovirus outbreaks reported in locations around PyeongChang affecting the local workforce. No significant prescribing trends for norovirus treatment were observed throughout the Games by the pharmacy team; norovirus was not a widespread problem within the athlete villages.

\section{Medication by sports}

There were a total of 1965 prescriptions dispensed during the Olympic Games and 395 prescriptions dispensed during the Paralympic Games. Athletes accounted for $15.3 \%$ and $8.4 \%$ among the total encounters at the Olympic and Paralympic Games, respectively (table 4).

\section{Medication by country}

A total of 2360 patients from 82 countries presented to the pharmacy during both the Olympic and Paralympic Games. Most countries (72 countries, $87.8 \%$ ) had fewer than 20 patient visits. The Republic of Korea represented the highest number of patient visits due to local workforce also 
Table 4 Number of pharmacy encounters of athletes by sports

\begin{tabular}{|c|c|c|}
\hline & Olympics $(n=300)$ & Paralympics $(n=33)$ \\
\hline Alpine skiing & 44 & 4 \\
\hline Biathlon & 22 & 1 \\
\hline Bobsleigh & 23 & NA \\
\hline Cross-country & 30 & 1 \\
\hline Curling/wheelchair curling & 16 & 4 \\
\hline Figure skating & 12 & NA \\
\hline Free style skiing & 23 & NA \\
\hline Ice hockey/ice sledge hockey & 43 & 4 \\
\hline Luge & 25 & NA \\
\hline Short track & 9 & NA \\
\hline Skating & 17 & NA \\
\hline Skeleton & 8 & NA \\
\hline Ski & 1 & 3 \\
\hline Ski jump & 2 & NA \\
\hline Snowboarding & 25 & 6 \\
\hline Unidentified & 0 & 10 \\
\hline
\end{tabular}

$\mathrm{NA}$, not available competition during the Paralympic Games.

accessing the service while they were working at the villages and venues (table 5).

\section{Work load during the games}

The Athletes' Villages opened a week prior to the opening ceremonies of both the Olympic and Paralympic Games. The number of prescriptions dispensed peaked 2 days prior to the Olympic Games opening ceremony and 1 day prior to the Paralympic Games opening ceremony. The lowest was on the day of the opening ceremony for each event (figure 1). These trends indicate that the pharmacy service should be ready and operational at least 4 weeks in advance of the opening ceremony to provide the medical care needed by the athletes on arrival to the villages. The pattern was similar in the Paralympic Games (figure 1).

\section{DISCUSSION}

The unique pharmacy setting of the Olympic and Paralympic Games highlights the importance of the pharmacists working together in a multidisciplinary fashion with the other clinical experts serving the needs of athletes in this specialised international and sports-medicine focused environment.

\section{Pharmacy operation}

Pharmacy services for the Games were centred on two pharmacies located in each of the athlete villages in PyeongChang, the Mountain area, and Gangneung, the Coastal area, each staging clusters of competition venues. The pharmacy in PyeongChang continued to serve the athletes during the Paralympic Games, where only one village was operational due to a smaller athlete population.

Table 5 The number of patient visits by the countries

\begin{tabular}{lc}
\hline Number of patient visits & Number of countries, $\mathbf{n}(\%)$ \\
\hline$\geq 50$ & $3(3.7)$ \\
$30-49$ & $1(1.2)$ \\
$20-29$ & $6(7.3)$ \\
$10-19$ & $15(18.3)$ \\
$<10$ & $57(69.5)$ \\
\hline
\end{tabular}

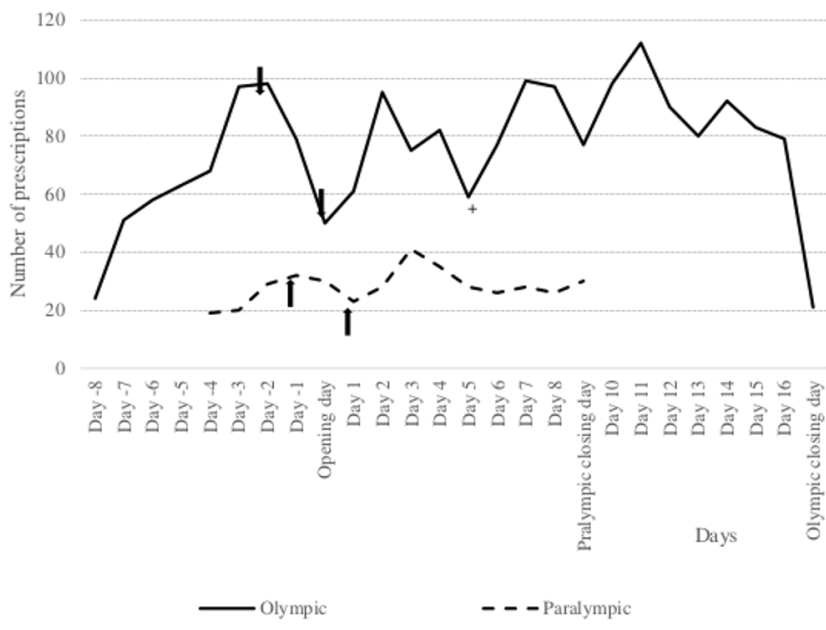

: Coastal polyclinic was closed due to the weather condition

Figure 1 The daily volume of prescriptions dispensed during the Olympic and Paralympic Games.

The pharmacists worked 8 hour shifts (7am-3pm and 3-11pm) with two pharmacists working each shift. A total of 17 volunteer pharmacists with backgrounds of community pharmacy, industry and hospital pharmacy worked for 2 to 4 weeks over the course of the Olympics or Paralympics. Ten of these pharmacists were allocated from two official designated hospitals: Wonju Severance Christian Hospital and Seoul National University Hospitals. A head pharmacist supervised the whole service and facilitated the relationship between the PyeongChang Organizing Committee for the 2018 Olympic and Paralympic Winter Games, the IOC and the IPC.

A pharmacy medication formulary of the Pharmacy Guide was developed by the head pharmacist in close collaboration with the IOC Medical Commission and IPC Medical Committee, respectively. It was based on the formulary used during the previous Olympic Games in London and Vancouver. However, it was adapted to reflect availability and medical practice in South Korea. The formulary contained 170 medications in 13 therapeutic categories. All medications were provided free of charge to athletes and officials at the games.

\section{Pharmacy roles and responsibility}

The main activities of pharmacists were as follows, but not limited to those listed here:

1. To review, prepare and dispense medications according to Korean, Olympic and Paralympic medical standards, respectively.

2. To counsel patients with specific needs and competing sports.

3. To provide drug information.

4. To support athletes in reviewing the medications on the WADA Prohibited List (http://www.wada-ama.org or https://www.globaldro.com) and receive TUE application and Needle Policy declaration.

5. To work closely with the IOC/IPC to facilitate medication-related issues when required.

6. To recommend medication substitutions for banned or non-formulary medications. 
7. To develop a system of supply, storage and management of medications for venues.

8. To dispense and deliver controlled medications at competition sites for athletes at high risk of injury.

9. To organise daily report data for a pharmacy vigilance.

10. To understand patient population which consisting of athletes and non-athletes who were the majority of pharmacy visitors.

The main roles of the head pharmacist were:

1. To act as a contact point between the pharmacy and international medical professionals to facilitate communication in a timely manner.

2. To establish the routine collaboration with interprofessional and intraprofessional relationships.

3. To coordinate the inspection of the pharmacy premises and venues.

4. To deliver information on medication use in sports to support the clinical requirements of high-performance athletes and to ensure that medications were used within the rules of the WADA Prohibited List.

5. To prepare the policies and procedures that comply with the legal obligations of drug management in Korea including Pharmacy Guide and Controlled Medication Policy.

\section{Challenges and future directions}

Most of the volunteer pharmacists had no previous work experience or training in sports events and thus, were unfamiliar with the prohibited substances and the process of TUE and Needle Policy. The pharmacy service facilitated the process for TUE and ensured that prohibited medications were not dispensed to athletes unless a TUE had been granted or the medication was needed for emergency medical treatment. The pharmacy team ensured that team physicians and athletes were aware of the policy and complied accordingly.

Our experience emphasised the importance of pre-games education and training on drugs used in sport and antidoping issues to enable pharmacists to confidently provide support to athletes in this context. ${ }^{8}$ The recently announced IOC Certificate in Drugs in Sport (www.sportsoracle.com) represents a beneficial new resource for pharmacists to obtain insights into their role and basic function in sports, especially in managing and advising on WADA prohibited medications. ${ }^{9}$ During the PyeongChang 2018 Games, pharmacists often have to recommend alternatives for WADA prohibited drugs, such as decongestants including pseudoephedrine and methylephedrine, which were prohibited for athlete use in competition. ${ }^{10}$ The status of glucocorticosteroid use was also questioned on a number of occasions by athletes to the pharmacy team, highlighting the fact that pharmacists have the responsibility to understand the WADA List of Prohibited Substances and Methods, so they can advise that corticosteroids are allowed for athletes only through specific routes of administration.

Competition venue access for individuals without the necessary permits was restricted, and transportation was very limited for pharmacists during the Games, which led to challenges in drug supply systems. In future games, the logistics of medication delivery around the competition sites should be planned well in advance. A designated courier system should be available for this function. An electronic inventory and systematic supply chain are recommended to manage the medication supply from both the polyclinic pharmacies and the competition venues.

When a host country does not use English as the first preferred language, which was the case in South Korea, having a pharmacy workforce mix including pharmacists proficient in English is extremely beneficial and might prevent any risk of error due to communication. Although athletes speak many languages in this environment, the majority had access to English-speaking team members who assisted in pharmacy communications. A 24-hour on-call service was available for the 2018 Games with the head pharmacist who was proficient in English.

Additionally, policy and procedures governing the polyclinic pharmacy should be prepared for all future games to ensure that pharmacists have a regulatory framework within which to operate professionally, in the context of sports, clinical and antidoping measures. The local legal regulations for prescriptions and controlled medication handling should be understood and implemented across all polyclinic pharmacies and competition venues where medications are available. Controlled medications are strictly regulated in many countries, and therefore, adequate preparation and planning should be ensured to comply with the regulations in advance.

Preventive measures to maintain a healthy environment in the Village was a significant priority for both the IOC medical commissions and IPC medical committee. To support this public health function, the pharmacy team actively monitored for any increase in medication orders or orders for unexpected medications from team physicians for reportable infectious symptoms by developing a daily dispensing report for both the IPC and IOC.

\section{CONCLUSION}

The pharmacists in the Olympic and Paralympic Games provided care and expertise to the high-performance athlete population. The services delivered under high intensity, high volume and short time required expert knowledge in antidoping, drugs used in sport, and sports pharmacy. Knowledge of professional work ethics and pre-training was key to deliver a safe and effective pharmacy service for Olympic and Paralympic athletes.

\section{What are the findings?}

- Pharmacy interventions can contribute to public health and prevent diseases outbreaks such as viral infections.

- In the Olympic and Paralympic environment, pharmacists require training and expert knowledge in antidoping, and the clinical use of drugs used in sport, and games-time policies such as the International Olympic Committee (IOC) Needle Policy and each IOC and International Paralympic Committee Therapeutic Use Exemption process.

How might it impact on clinical practice in the future?

- Our research provides practical insights into the pharmacy operations and a role as a member of the multidisciplinary team of physicians, nurses, other healthcare professionals and international/national medical committee members.

- Pharmacists should focus on preventive measures of potential health risks at large multisport events.

- Pre-training of professional ethics, good communication and knowledge of drugs used in sports is essential to deliver a safe and effective pharmacy service.

Acknowledgements The authors thank all pharmacists who worked at PyeongChang Olympic and Paralympic Games for their diligent efforts, perseverance and work ethics. Olympic and Paralympic pharmacists (in alphabetical order with last names): Sue-Jeong Baik, RPh, Yoon Sook Cho, RPh, Ji Hyun Choi, Pharm D, 
Min Hyeong Joo, Pharm D, You Na Kang, Pharm D, Boram Kim, Pharm D, Eun Jin Kim, PharmD, Eun Sun Kim, RPh, Hyun Ah Kim, Pharm D, Jeong Ran Kim, Pharm D, Ahrim Lee, Pharm D, Hyun Ah Lee, Pharm D, Kyung Joo Lee, Pharm D, Mira Moon, RPh, Hyojoo Nam, Pharm D, Dag Noh, Pharm D, Yu Jin Oh, Pharm D, Kyoungryul Park, Pharm D, and Mi Hyun You, Pharm D. Special thanks are due to Olympic and Paralympic pharmacists, and members of the Medical \& Scientific Committee (in alphabetical order with last names): Goo Hyun Baek, MD (POCOG), Cheri Blauwet, MD (IPC), Richard Budgett, MD (IOC), Young Hee Lee, MD (POCOG), and Peter Van de Vliet, PhD (IPC). They appreciate Rose Kim who gave crucial comments on the content of manuscript throughout the process and her English editing; Ms Kay Youngstrom, who worked as an intern of clinical pharmacy laboratory at Ewha Womans University, diligently edited the manuscript for English language.

Contributors SJR: involved in planning the study, reviewed and analysed the literature, wrote the paper, draft and approved the final version. MS: critically revised the article and approved the final version. YIK: involved in planning the study, collecting data and approved the final version.

Funding The research was supported by Ewha University-Industry Collaboration Foundation of Ewha Womans University (1-2018-0317-001-1). The publication was financially supported by the Yonsei Institute of Sports Science and Exercise Medicine (YISSEM).

Competing interests None declared.

Patient consent for publication Not required.

Ethics approval The IOC Medical \& Scientific Commission and the IPC Medical Committee.

Provenance and peer review Not commissioned; externally peer reviewed.

Data sharing statement Data will be available upon request.

Open access This is an open access article distributed in accordance with the Creative Commons Attribution Non Commercial (CC BY-NC 4.0) license, which permits others to distribute, remix, adapt, build upon this work non-commercially, and license their derivative works on different terms, provided the original work is properly cited, appropriate credit is given, any changes made indicated, and the use is non-commercial. See: http://creativecommons.org/licenses/by-nc/4.0/.

\section{REFERENCES}

1 Stuart M, Mottram D, Erskine D, et al. Development and delivery of pharmacy services for the London 2012 Olympic and Paralympic Games: Table 1. Eur J Hosp Pharm 2013:20:42-5.

2 File H, Thomas T, Anderson G. Case study of the London 2012 Olympic and Paralympic pharmacy service preparations. Int J Pharm Pract 2015;23:212-20.

3 Skouroliakou M, Kani C, Kompogiorgas S, et al. Drug consumption during the 2004 Olympics: the special Olympic Pharmacy. Pharm World Sci 2005;27:478-9.

4 Vanhegan IS, Palmer-Green D, Soligard T, et al. The London 2012 Summer Olympic Games: an analysis of usage of the Olympic Village 'Polyclinic' by competing athletes. Br J Sports Med 2013:47:415-9.

5 Stuart M, Mottram D, Thomas T. Innovations in Olympic and paralympic pharmacy services. Br J Sports Med 2013;47:404-6.

6 The World Anti-Doping Agency (WADA). Prohibited List. http://www.wada-ama.org (Accessed on 5 Apr 2018).

7 Wagner JC, Ulrich LR, McKean DC, et al. Pharmaceutical services at the tenth pan American Games. Am J Hosp Pharm 1989;46:2023-7.

8 Ambrose PJ. Drug use in sports: a veritable arena for pharmacists. J Am Pharm Assoc 2004:44:501-16. quiz 514-6.

9 International Olympic Committee, Sportsoracle. IOC Certificate in Drugs in Sport. https://www.sportsoracle.com.

10 Alaranta A, Alaranta H, Heliövaara M, et al. Allergic rhinitis and pharmacological management in elite athletes. Med Sci Sports Exerc 2005;37:707-11. 